\title{
openheart High prevalence of undiagnosed COPD among patients evaluated for suspected myocardial ischaemia
}

\author{
Andreas Jönsson,,$^{1,2}$ Artur Fedorowski, ${ }^{1,3}$ Gunnar Engström, ${ }^{1}$ Per Wollmer, ${ }^{4,5}$ \\ Viktor Hamrefors ${ }^{1,2}$
}

To cite: Jönsson A, Fedorowski A, Engström G, et al. High prevalence of undiagnosed COPD among patients evaluated for suspected myocardial ischaemia. Open Heart 2018;5:e000848. doi:10.1136/ openhrt-2018-000848

Received 7 May 2018

Revised 23 August 2018

Accepted 26 September 2018

Check for updates

(c) Author(s) (or their employer(s)) 2018. Re-use permitted under CC BY-NC. No commercial re-use. See rights and permissions. Published by BMJ.

${ }^{1}$ Department of Clinical Sciences, Lund University, Malmö, Sweden

${ }^{2}$ Department of Internal Medicine, Skåne University Hospital, Malmö, Sweden ${ }^{3}$ Department of Cardiology, Skåne University Hospital, Malmö, Sweden

${ }^{4}$ Department of Translational Medicine, Lund University, Malmö, Sweden

${ }^{5}$ Department of Medical Imaging and Physiology, Skåne University Hospital, Malmö, Sweden

Correspondence to Dr Viktor Hamrefors; viktor. hamrefors@med.lu.se

\section{ABSTRACT}

Objective Chronic obstructive pulmonary disease (COPD) and coronary artery disease (CAD) are leading causes of global morbidity and mortality. Despite the well-known comorbidity between COPD and CAD, the presence of COPD may be overlooked in patients undergoing coronary evaluation. We aimed to assess the prevalence of undiagnosed COPD among outpatients evaluated due to suspected myocardial ischemia.

Methods Among 500 outpatients who were referred to myocardial perfusion imaging due to suspected stable myocardial ischaemia, 433 patients performed spirometry. Of these, a total of 400 subjects (age 66 years; $45 \%$ women) had no previous COPD diagnosis and were included in the current study. We compared the prevalence of previously undiagnosed COPD according to spirometry criteria from The Global Initiative for Chronic Obstructive Lung Disease (GOLD) or lower limit of normal (LLN) and reversible myocardial ischaemia according to symptoms and clinical factors.

Results A total of 134 (GOLD criteria; $33.5 \%$ ) or 46 patients (LLN criteria; $11.5 \%$ ) had previously undiagnosed COPD, whereas 55 patients (13.8\%) had reversible myocardial ischaemia. The presenting symptoms (chest discomfort, dyspnoea) did not differ between COPD, myocardial ischaemia and normal findings. Except for smoking, no clinical factors were consistently associated with previously undiagnosed COPD.

Conclusions Among middle-aged outpatients evaluated due to suspected myocardial ischaemia, previously undiagnosed COPD is at least as common as reversible myocardial ischaemia and the presenting symptoms do not differentiate between these entities. Patients going through a coronary ischaemia evaluation should be additionally tested for COPD, especially if there is a positive history of smoking.

\section{INTRODUCTION}

Chronic obstructive pulmonary disease (COPD) and coronary artery disease (CAD) are both leading causes of global morbidity and mortality. ${ }^{1}$ There is a strong association between reduced pulmonary function and cardiovascular disease mortality in the population, ${ }^{2}{ }^{3}$ and there exists a strong comorbidity between COPD and CAD in patients

\section{Key questions}

What is already known about this subject?

- There exists a strong comorbidity between coronary artery disease (CAD) and chronic obstructive pulmonary disease (COPD), which is why clinical guidelines recommend that the risk of CAD shall be assessed in all patients with COPD. On the contrary, despite the fact that COPD is thought to be considerably underdiagnosed, there are no clear recommendations for assessing COPD in patients with CAD or with symptoms initially suggestive of CAD.

What does this study add?

- In this study, we show that in middle-aged patients who were clinically evaluated due to suspected myocardial ischaemia, previously undiagnosed COPD can be found in $10 \%-30 \%$ of patients, depending on the applied criteria. In these patients, previously unrecognised airflow obstruction is at least as common as the reversible myocardial ischaemia. There is very little overlap between airflow obstruction and myocardial ischaemia and the presenting symptoms do not differentiate between these two entities.

How might this impact on clinical practice?

- Patients with unexplained symptoms suggestive of stable myocardial ischaemia may benefit from additional respiratory function tests in the form of dynamic spirometry, especially if there is a positive history of smoking.

with pulmonary or cardiovascular disease, respectively. ${ }^{4-7}$ These associations may be partly explained by common risk factors, most notably smoking. ${ }^{8}$ However, a significant proportion of patients with COPD as well as $\mathrm{CAD}$ are reported as never smokers ${ }^{9}$ and a number of additional common risk factors for COPD and CAD have been suggested, including genetic factors, ${ }^{10}$ airborne pollution, ${ }^{11}$ low-grade inflammation ${ }^{12}$ and cardiovascular autonomic dysfunction. ${ }^{13}$

Recognising the strong comorbidity and common risk factors present in both COPD and $\mathrm{CAD},{ }^{14}$ it has been recommended that the risk of subclinical or overt CAD shall be 
assessed in all patients with COPD ${ }^{15}$ Conversely, recent guidelines also emphasise the value of lung function testing in patients with manifest CAD and other heart disease, even though this has been less established in clinical practice. ${ }^{16}$

From a clinical perspective, patients usually present with unexplained symptoms, not established diagnoses. Symptoms indicating pathology of the cardiopulmonary system, such as chest discomfort and dyspnoea, are common presenting symptoms to physicians in a wide variety of medical specialties and settings. Especially, in the case of known CAD or when the traditional CAD risk factors are present, these symptoms often raise suspicion of underlying myocardial ischaemia, which is why these patients often go through extensive coronary evaluation, including non-invasive ischaemia testing such as myocardial perfusion imaging. Such evaluation has a high sensitivity for reversible ischaemia ${ }^{17}{ }^{18}$; however, in the vast majority of patients, even with known CAD, no underlying coronary cause of the symptoms can be identified. ${ }^{19}$ Often, the investigation is terminated when myocardial ischaemia has been ruled out, and it is not uncommon that the symptoms are left unexplained. Accounting for the extensive comorbidity that exists between CAD and COPD and the fact that symptoms of COPD may be diffuse, especially at early stages, we hypothesised that undiagnosed COPD is common and may be missed in significant proportion of patients presenting symptoms suggestive of myocardial ischaemia. Thus, we performed pulmonary function testing with dynamic spirometry in outpatients with and without known CAD that had been referred to myocardial perfusion imaging due to suspected myocardial ischaemia. We then related the results from myocardial perfusion imaging and spirometry with the presenting symptoms and assessed clinical factors associated with previously undiagnosed COPD according to spirometry criteria.

\section{METHODS}

\section{Patients and baseline data acquisition}

The subjects of the current study were all participants of the Swedish Biomarkers and Genetics CardioPulmonary Physiology Study (BiG CaPPS) cohort, which is a patient cohort study focused on the comorbidity between cardiovascular and respiratory disease. The BiG CaPPS cohort consists of a total of 500 outpatients with suspected stable myocardial ischaemia, all of whom had been clinically referred by a physician to myocardial perfusion imaging (MPI) at the Department of Clinical Physiology and Nuclear Medicine at Skåne University Hospital in Malmö, Sweden, between June 2014 and October 2017 (59\% inclusion rate). The BiG CaPPS cohort includes only outpatients with suspected stable myocardial ischaemia, meaning that subjects with potential acute coronary syndrome were not included. Except for inability to provide written informed consent, there were no further exclusion criteria in BiG CaPPS.
At the time of enrolment into BiG CaPPS, which occurred on the same day as the clinical MPI, the subjects answered a questionnaire including medical history and a detailed assessment of smoking history. Additional information was retrieved from the study participants' medical records, including referring physician's unit (cardiology, internal medicine, general practitioner or 'other') and the underlying indication for the MPI. The latter were categorised into any of seven categories, of which a maximum of two main reasons were recorded for each subject. These categories were chest discomfort, dyspnoea, pathological ECG at exercise or at rest, arrhythmia evaluation, heart failure evaluation, guidance for revascularisation and other. Resting blood pressure and heart rate were recorded prior to the MPImyocardial perfusion imaging.

Of 500 patients initially enrolled in BiG CaPPS, MPI could not be completed in one patient due to very high blood pressure and 20 patients withdrew from the study after the MPI had been performed. Moreover, eight patients had already performed a recent clinical spirometry and 38 did not accept spirometry for the study. Of the remaining 433 patients, 400 subjects that had no previously known COPD diagnosis according to the questionnaire and/or their medical records at the time of enrolment were eligible for inclusion in the current study (figure 1).

\section{Myocardial perfusion imaging}

The MPI tests were performed on clinical grounds in all patients, hence these tests followed the clinical procedure and guidelines ${ }^{2021}$ implemented at the Department of Clinical Physiology and Nuclear Medicine at Skåne University Hospital in Malmö, Sweden. The protocol, which has been previously described in detail, ${ }^{22}$ included provocation with either exercise on a bicycle or pharmacological provocation with adenosine or regadenosone, after which ${ }^{99 \mathrm{~m}}$ Tc-tetrofosmin was injected and corresponding coronary perfusion images were acquired by single-photon emission CT (SPECT). Images were obtained according to established clinical protocols, using SPECT and dual-head gamma camera (Siemens AG Medical Solutions, Erlangen, Germany) with attenuation correction. The results were interpreted by physicians with special experience in MPI at the department, after which the reports were sent to the referring physicians.

\section{Pulmonary function testing and COPD definitions}

Pulmonary function testing including dynamic spirometry after bronchodilation was performed on a separate day, usually within 1 month after MPI. The examination was performed according to European guidelines ${ }^{23}$ that had been implemented at the Department of Clinical Physiology and Nuclear Medicine at Skåne University Hospital, Malmö, Sweden using a standard equipment (Jaeger, Würzburg, Germany). Subjects were asked to refrain from smoking for 4 hours before the examination.

In the current study, COPD (hereafter termed 'COPD' throughout the manuscript) was defined according to 


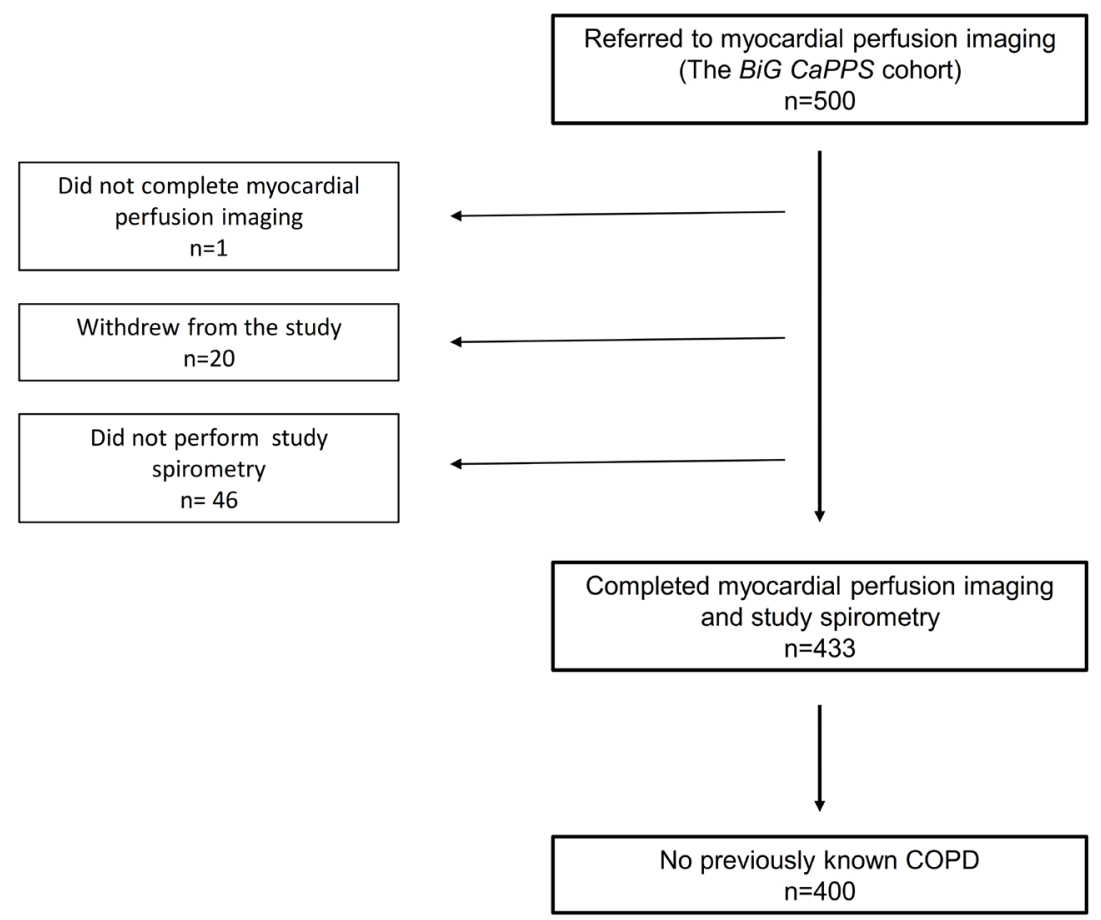

Figure 1 Study flowchart. The selection of patients for the current study. BIG CaPPS, Biomarkers and Genetics CardioPulmonary Physiology Study; COPD, chronic obstructive pulmonary disease.

spirometry criteria as a ratio of $\mathrm{FEV}_{1}$ to $\mathrm{VC}<0.70^{24}$ or below the lower limit of normal (LLN; $<1.645$ SD of the predicted value) according to Swedish reference equations that are used at the Department of Clinical Physiology and Nuclear Medicine in Malmö. ${ }^{25}{ }^{26}$ Moreover, all tests, including visual flow-volume curves were interpreted by one of two physicians with extensive experience from lung function testing $(\mathrm{VH}, \mathrm{PW})$. The severity of airflow obstruction was graded as mild $\left(\mathrm{FEV}_{1} \geq 70 \%\right.$ of predicted), moderate $\left(\mathrm{FEV}_{1} 50 \%-69 \%\right.$ of predicted) or severe $\left(\mathrm{FEV}_{1}<50 \%\right.$ of predicted) according to the classification by European Respiratory Society. ${ }^{27}$ In case of reduced $\mathrm{VC}$ or $\mathrm{FEV}_{1}$ but normal $\mathrm{FEV}_{1}: \mathrm{VC}$ ratio and no signs of airflow obstruction by visual inspection of the flow-volume curves, the spirometry was interpreted as non-specific lung function reduction.

\section{Statistics}

According to the results from MPI and spirometry, respectively, all subjects were grouped into one of five diagnostic groups: COPD but no reversible ischaemia (COPD+/ischaemia-); no COPD but reversible ischaemia (COPD-/ischaemia+); both COPD and reversible ischaemia $(C O P D+/$ ischaemia +$)$; non-specific pulmonary function reduction and no ischaemia (other spirometry finding/ischaemia-); normal findings at both MPI and spirometry (normal findings). Continuous variables (of which all were normally distributed) were compared between the different diagnosis groups using one-way ANOVA tests in the case of homogeneity of variance between groups, by using Levene's test. If the rule of homogeneity of variance between groups was violated (Levene's test $\mathrm{p}<0.05$ ), a Welch ANOVA test was performed. If ANOVA or Welch ANOVA displayed significant overall findings between the groups, post hoc tests for differences between the groups was performed with Tukey's test or Games-Howell test (in the case of inhomogeneity of variance between groups). Dichotomous variables were compared between the groups using $\chi^{2}$ tests.

The relations between a number of clinical factors (age, sex, smoking, known CAD, Body Mass Index (BMI), dyslipidaemia, presenting symptoms, referring unit, ischaemia on MPI) at time of referral and COPD according to spirometry criteria were assessed using univariable logistic regression, with COPD (Global Initiative for Chronic Obstructive Lung Disease (GOLD) or LLN) entered as the dependent variable. The results are shown as the OR with $95 \%$ CI.

All descriptive statistics are presented as mean (SD) unless otherwise specified. All tests were two-sided where $p<0.05$ was considered statistically significant.

All statistical analyses were done by SPSS Statistics V.25.0 from IBM.

\section{RESULTS}

\section{Patient characteristics}

The characteristics of the 400 patients who were included are shown in table 1 . In summary, the patients were middle-aged and slightly more men than women were 


\begin{tabular}{|c|c|}
\hline Age, years & $66.2(10.5)$ \\
\hline Sex, \% women & 44.8 \\
\hline \multicolumn{2}{|l|}{ Smoking status } \\
\hline Never smoker & 35.3 \\
\hline Ex smoker & 52.9 \\
\hline Current smoker & 11.8 \\
\hline Body Mass Index, kg/m² & $28.4(4.6)$ \\
\hline Dyslipidaemia, \% & 38.3 \\
\hline Systolic blood pressure, mm Hg & $138.8(17.4)$ \\
\hline Diastolic blood pressure, $\mathrm{mm} \mathrm{Hg}$ & $80.0(9.1)$ \\
\hline Resting heart rate, bpm & $69.4(11.7)$ \\
\hline Known $\mathrm{CAD}$ at time of referral, $\%$ & 34.1 \\
\hline \multicolumn{2}{|l|}{ Referred by, \% } \\
\hline Cardiology unit & 33.0 \\
\hline Internal medicine unit & 14.8 \\
\hline General practitioner & 21.5 \\
\hline Other & 30.7 \\
\hline \multicolumn{2}{|l|}{ Main indications for ischaemia evaluation (any of), \% } \\
\hline Chest discomfort & 72.3 \\
\hline Dyspnoea & 17.8 \\
\hline Guidance for PCl & 2.8 \\
\hline Heart failure evaluation & 2.3 \\
\hline Resting or exercise ECG suspect of ischaemia & 23.8 \\
\hline Arrhythmia evaluation & 5.5 \\
\hline Other indication & 9.3 \\
\hline \multicolumn{2}{|l|}{ Myocardial perfusion imaging protocol } \\
\hline Exercise & 30.8 \\
\hline Pharmacological provocation & 69.2 \\
\hline
\end{tabular}

Displayed as mean (SD) unless otherwise specified.

$\mathrm{CAD}$, coronary artery disease; $\mathrm{PCl}$, percutaneous coronary intervention.

included. Approximately two-thirds of patients were ever smokers, whereas the rate of current smoking at the time of inclusion was $11.8 \%$. A majority of the patients had been referred to MPI from a cardiology unit, and one-third had known CAD already at time of referral. The most common indication for MPI was chest discomfort, followed by an ECG suggestive of ischaemia either at rest or during exercise.

\section{Results from the MPI and spirometry}

A total of 134 subjects $(33.5 \%)$ fulfilled the spirometry criteria for COPD according to GOLD whereas 55 patients $(13.8 \%)$ had reversible myocardial ischaemia. Only 12 patients $(3.0 \%)$ had both COPD and myocardial ischaemia (table 2A). In the group diagnosed with COPD according to GOLD criteria, $82.8 \%$ had mild, $14.2 \%$ had moderate and $3.0 \%$ had severe airflow obstruction, respectively.
Applying LLN criteria, COPD could be diagnosed in 46 patients $(11.5 \%)$. Only four patients $(1.0 \%)$ had both COPD and myocardial ischaemia (table $2 \mathrm{~B}$ ). In the group with COPD according to LNN criteria, $63.0 \%$ had mild, $28.3 \%$ had moderate and $8.7 \%$ had severe obstruction, respectively.

Regardless of whether GOLD or LLN criteria were used, approximately $5 \%$ of the patients had a non-specific lung function reduction, that is, pathological spirometry without evidence of airflow obstruction (tables 2A and 2B).

Among the 55 patients with myocardial ischaemia, 32 $(58 \%)$ had known CAD already at the time of referral. Furthermore, among the patients with myocardial ischaemia, COPD was diagnosed in 21.8\% (GOLD) and $7.3 \%$ (LLN), respectively. The same proportions in patients without myocardial ischaemia were $35.4 \%$ (GOLD) and $12.2 \%$ (LLN). The proportion of patients fulfilling GOLD criteria was significantly higher among patients without ischaemia $(p=0.048)$ whereas the proportion of patients fulfilling the LLN criteria $(\mathrm{p}=0.29)$ did not differ significantly between patients with and without myocardial ischaemia, respectively.

\section{Clinical factors associated with previously undiagnosed COPD}

Age, sex, the proportion of ever smokers, the proportion of patients with known CAD, spirometry values and BMI differed significantly between the diagnoses groups stratified according to GOLD criteria (table 2A). If the two groups with relatively small numbers ('COPD+ischaemia+' and 'other spirometry finding') were excluded, the results did not change substantially. Subjects with undiagnosed COPD without ischaemia were older $(\mathrm{p}<0.001)$ and had higher BMI $(\mathrm{p}=0.029)$ than subjects with normal findings. Results were similar for subjects with undiagnosed COPD and ischaemia who were older $(\mathrm{p}=0.008)$ and had higher BMI $(p=0.014)$ compared with subjects with normal findings. Subjects with undiagnosed COPD had higher BMI than subjects with normal findings. Moreover, subjects with undiagnosed $\mathrm{COPD} \pm$ ischaemia or non-specific pathological spirometry findings had lower $\mathrm{FEV}_{1}$ than subjects with normal findings $(p<0.001)$. Subjects with non-specific pathological spirometry findings $(p<0.001)$ and undiagnosed COPD+ischaemia $(\mathrm{p}=0.041)$ had lower VC than subjects with normal findings.

The proportion of women, the proportion of ever and current smokers, the proportion of known CAD, spirometry values and BMI differed significantly between the diagnoses groups according to LLN criteria (table 2B). The results did not change substantially if the two groups with small numbers ('COPD+ischaemiat' and 'other spirometry finding') were excluded from the statistical analysis. Subjects with undiagnosed $\mathrm{COPD} \pm$ ischaemia or non-specific pathological spirometry findings had lower FEV than subjects with normal findings $(\mathrm{p}<0.001)$ whereas subjects with non-specific pathological spirometry findings had lower VC than subjects with normal findings $(\mathrm{p}<0.001)$. 
Table 2A Clinical characteristics and presenting symptoms according to diagnoses (GOLD criteria)

\begin{tabular}{|c|c|c|c|c|c|c|}
\hline & $\begin{array}{l}\text { COPD+ } \\
\text { Ischaemia- } \\
(n=122)\end{array}$ & $\begin{array}{l}\text { COPD- } \\
\text { Ischaemia+ } \\
(n=43)\end{array}$ & $\begin{array}{l}\text { COPD+ } \\
\text { Ischaemia+ } \\
(\mathrm{n}=12)\end{array}$ & $\begin{array}{l}\text { Other } \\
\text { spirometry } \\
\text { finding } \\
\text { Ischaemia- } \\
(\mathrm{n}=20)\end{array}$ & $\begin{array}{l}\text { Normal findings } \\
(\mathrm{n}=203)\end{array}$ & P values \\
\hline Age, years & $69.5(8.9)$ & $64.7(7.5)$ & $72.3(6.2)$ & $64.4(11.9)$ & $64.4(11.4)$ & $0.001^{*}$ \\
\hline Sex, \% women & 50.0 & 22.7 & 9.1 & 40.0 & 48.6 & 0.002 \\
\hline Ever smoker, \% & 71.7 & 76.7 & 91.7 & 60.0 & 56.9 & 0.006 \\
\hline Current smoker, \% & 15.0 & 14.0 & 25.0 & 10.0 & 8.9 & 0.282 \\
\hline History of CAD, \% & 33.6 & 51.2 & 83.3 & 55.0 & 25.7 & $<0.001$ \\
\hline Chest discomfort, \% & 71.3 & 72.1 & 83.3 & 60.0 & 73.4 & 0.659 \\
\hline Dyspnoea, \% & 18.9 & 14.0 & 8.3 & 5.0 & 19.7 & 0.404 \\
\hline $\mathrm{FEV}_{1}, \%$ of predicted & 83.1 (14.9) & $97.8(14.7)$ & 73.7 (15.5) & $81.3(12.1)$ & $99.0(13.1)$ & $<0.001$ \\
\hline VC, $\%$ of predicted & $97.0(15.1)$ & 92.7 (11.6) & 84.5 (11.1) & $75.4(8.9)$ & $95.4(12.0)$ & $<0.001^{*}$ \\
\hline $\mathrm{BMI}, \mathrm{kg} / \mathrm{m}^{2}$ & $29.1(4.7)$ & $30.0(4.7)$ & $27.4(3.3)$ & $30.4(5.3)$ & $27.6(4.4)$ & 0.001 \\
\hline Dyslipidaemia, \% & 38.5 & 51.2 & 58.3 & 45.0 & 33.5 & 0.115 \\
\hline SBP, mm Hg & $140.0(16.7)$ & $141.3(17.8)$ & $141.7(16.4)$ & $141.3(15.0)$ & $137.2(18.0)$ & 0.421 \\
\hline $\mathrm{DBP}, \mathrm{mm} \mathrm{Hg}$ & $80.3(8.4)$ & $81.0(8.0)$ & $77.5(8.4)$ & 81.8 (11.9) & $79.5(9.4)$ & 0.573 \\
\hline Heart rate, bpm & 70.8 (12.1) & 70.5 (10.8) & 72.8 (13.2) & 70.0 (13.3) & 68.1 (11.3) & 0.214 \\
\hline
\end{tabular}

$P$ values are reported for ANOVA test for continuous variables and $\chi^{2}$ for dichotomous variables, unless otherwise specified.

${ }^{*} \mathrm{P}$ value reported for Welch ANOVA test due to inhomogeneity of variances between groups.

BMI, Body Mass Index; CAD, coronary artery disease; COPD, chronic obstructive pulmonary disease; DBP, diastolic blood pressure; GOLD,

The Global Initiative for Chronic Obstructive Lung Disease; SBP, systolic blood pressure.

In logistic regression models, age and ever smoking were two factors associated with undiagnosed COPD according to GOLD criteria, whereas female sex and current smoking were the only factors associated with undiagnosed COPD according to LLN (table 4). Presenting symptoms in the form of chest discomfort

Table 2B Clinical characteristics and presenting symptoms according to diagnoses (LLN criteria)

\begin{tabular}{llllllc}
\hline & $\begin{array}{l}\text { COPD+ } \\
\text { Ischaemia }- \\
\text { (n=42) }\end{array}$ & $\begin{array}{l}\text { COPD - } \\
\text { Ischaemia + } \\
\text { (n=51) }\end{array}$ & $\begin{array}{l}\text { COPD+ } \\
\text { ischaemia + }\end{array}$ & $\begin{array}{l}\text { (n=4) } \\
\text { Other spirometry } \\
\text { finding+ } \\
\text { Ischaemia - } \\
(\mathbf{n = 2 2})\end{array}$ & $\begin{array}{l}\text { Normal findings } \\
\text { (n=281) }\end{array}$ & P values \\
\hline Age, mean (SD) & $67.7(10.3)$ & $66.4(8.1)$ & $65.8(4.6)$ & $65.3(11.7)$ & $66.1(10.9)$ & 0.902 \\
\hline Sex, \% women & 61.9 & 19.6 & 25 & 36.4 & 47.7 & $<0.001$ \\
\hline Ever-smoker, \% & 73.2 & 78.4 & 100 & 63.6 & 60.6 & 0.044 \\
\hline Current-smoker, \% & 24.4 & 13.7 & 50 & 9.1 & 9.3 & 0.008 \\
\hline Known CAD, \% & 31 & 54.9 & 100 & 59.1 & 27.9 & $<0.001$ \\
\hline Chest discomfort, \% & 61.9 & 76.5 & 50 & 63.6 & 74 & 0.294 \\
\hline Dyspnea, \% & 21.4 & 11.8 & 25 & 9.1 & 18.9 & 0.533 \\
\hline FEV1 \% of predicted & $74.8(15.1)$ & $95.1(15.3)$ & $59.5(15.4)$ & $78.9(13.9)$ & $96.0(13.6)$ & $<0.001$ \\
\hline VC \% of predicted & $97.5(17.0)$ & $91.9(11.3)$ & $78.9(13.8)$ & $73.7(10.1)$ & $96.0(12.2)$ & $<0.001^{*}$ \\
\hline BMI, kg * m-2 & $29.2(5.2)$ & $29.7(4.5)$ & $26.1(4.6)$ & $30.1(5.1)$ & $28.0(4.4)$ & 0.023 \\
\hline Dyslipidaemia, \% & 38.1 & 52.9 & 50 & 40.9 & 35.2 & 0.196 \\
\hline SBP, mmHg & $138.1(16.2)$ & $142.2(17.3)$ & $131.3(17.0)$ & $142.7(15.3)$ & $138.1(17.7)$ & 0.37 \\
\hline DBP, mmHg & $79.9(8.3)$ & $79.8(8.2)$ & $85.0(5.8)$ & $82.1(12.3)$ & $79.7(9.1)$ & 0.624 \\
\hline Heart rate, bpm & $72.5(11.7)$ & $71.0(11.2)$ & $70.3(14.1)$ & $70.9(14.2)$ & $68.5(11.5)$ & 0.23 \\
\hline
\end{tabular}

$P$ values are reported for ANOVA test for continuous variables and $\chi^{2}$ for dichotomous variables, unless otherwise specified.

${ }^{*} \mathrm{P}$ value reported for Welch ANOVA test due to inhomogeneity of variances between groups.

BMI, Body Mass Index; CAD, coronary artery disease; DBP, diastolic blood pressure; LLN, lower limit of normal; SBP, systolic blood pressure. 
Table 3 Factors associated with previously undiagnosed COPD

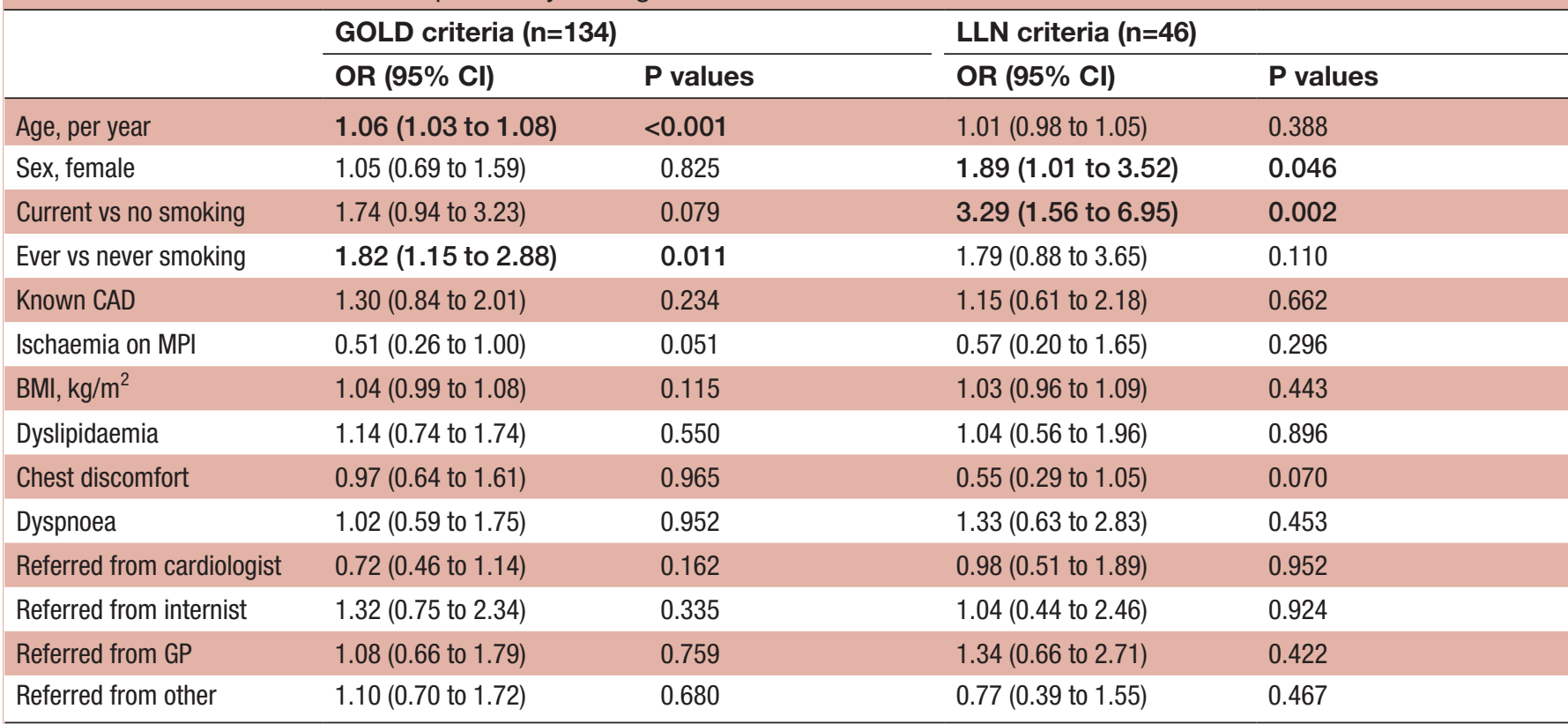

Bold indicates significant association.

CAD, coronary artery disease; COPD, chronic obstructive pulmonary disease; GOLD, The Global Initiative for Chronic

Obstructive Lung Disease; GP, general practitioner; LLN, lower limit of normal; MPI, myocardial perfusion imaging.

or dyspnoea did not associate with undiagnosed COPD (table 4). Moreover, chest discomfort and dyspnoea were prevalent in a similar proportion of patients in each of the diagnosis groups (table $2 \mathrm{~A}$ and $2 \mathrm{~B}$, figure 2 ).

\section{DISCUSSION}

In this study, we demonstrated a high prevalence of previously undiagnosed airflow obstruction in outpatients

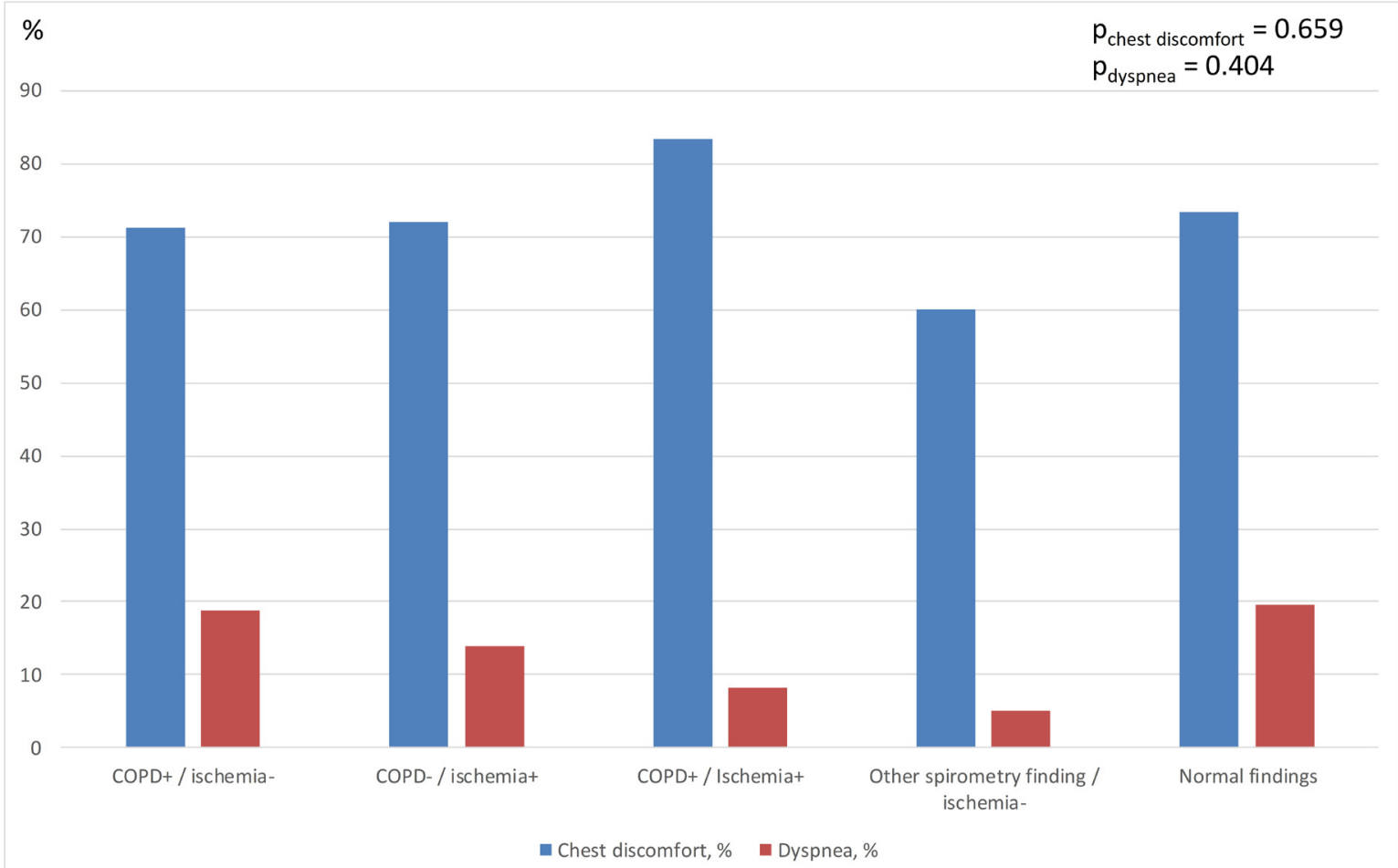

Figure 2 Main presenting symptoms according to the diagnoses groups. Presenting symptoms (\% of patients within each diagnosis group) according to diagnoses (Global Initiative for Chronic Obstructive Lung Disease criteria). $\mathrm{P}$ values denote differences in proportions between all groups according to $\chi^{2}$ test. 
evaluated due to suspected stable myocardial ischaemia. Depending on whether GOLD or LLN criteria were used, the prevalence of previously undiagnosed COPD according to spirometry criteria ranged from $11 \%$ to $30 \%$. At the same time, despite the fact that suspected myocardial ischaemia constituted the inclusion criteria for the current study and one-third of the patients had known CAD at time of inclusion, reversible ischaemia was diagnosed in only $14 \%$. Patients eventually diagnosed with COPD or ischaemia, respectively, had similar proportions of main presenting symptoms, meaning that symptoms such as chest discomfort or dyspnoea did not differentiate between a final diagnosis of COPD or reversible myocardial ischemia.

The strong comorbidity between CAD and COPD is well known from several previous studies. ${ }^{4-7}$ Furthermore, whereas airflow obstruction has been shown to be a common finding among patients with manifest $\mathrm{CAD},{ }^{67}$ we are not aware of any previous study that used a pragmatic symptom-based approach similar to our design. Except for age (for GOLD criteria), female sex (for LLN criteria) and smoking history (both GOLD and LLN), none of the examined clinical factors at the time of referral was associated with COPD.

The high prevalence of previously undiagnosed COPD among patients who were primarily evaluated for myocardial ischaemia conveys at least two main clinical implications. First, our findings emphasise that clinicians should be aware of the possible differential diagnosis of COPD in the case of a negative coronary work-up, which is very common in clinical practice. ${ }^{19}$ Second, middle-aged patients who present with symptoms initially suggestive of myocardial ischaemia are suitable for COPD screening, especially when there is a history of smoking. COPD, in particular in its early stage, is thought to be considerably underdiagnosed, ${ }^{28}$ and our current study suggests that patients with unexplained chest symptoms and dyspnoea are likely to have an undiagnosed COPD according to spirometry criteria. The fact that a large majority of the patients had only mild airflow obstruction, representing early or preclinical COPD, also points out that this group of patients might be a suitable target for early interventions, most notably intensive smoke stop interventions. ${ }^{24}$

In this cohort, there was a sizable difference in the proportion of patients meeting the spirometry criteria for COPD according to GOLD and LLN, the former resulting in almost three times more subjects having previously undiagnosed COPD. Compared with the conclusions from an expert panel, GOLD criteria tend to overdiagnose COPD whereas LLN underestimate COPD in elderly patients. ${ }^{29}$ The subjects of the current study were relatively young, meaning that the problem of overdiagnosis with GOLD should be less pronounced. On the other hand, the recent guidelines from GOLD ${ }^{24}$ also include respiratory symptoms as well as potential underlying exposures to noxious particles or gases for the diagnosis of COPD. If these factors were to be taken into account, the prevalence of COPD according to GOLD is likely to be lower in our study. Naturally, in clinical practice, such factors should be considered, regardless of whether the spirometry for COPD is based on GOLD or LLN. Furthermore, a great majority of the subjects with undiagnosed COPD according to GOLD in our study had only mild airway obstruction $\left(\mathrm{FEV}_{1}>70 \%\right.$ of predicted) and half of the subjects had only a slightly reduced $\mathrm{FEV}_{1}: \mathrm{VC}$ ratio $(0.65-0.69)$. In addition, the COPD diagnosis may be of greater clinical significance when both criteria are fulfilled. $^{30}$

In the current study, the combination of myocardial ischaemia and COPD was very rare, with a prevalence of only a few per cent. Among subjects diagnosed with myocardial ischaemia, COPD was not more common than in patients without myocardial ischaemia. Indeed, there was a trend for a lower COPD prevalence among patients with ischaemia compared with patients without ischaemia. There are a number of possible explanations that may partly underlie these findings. First, subjects with symptoms of angina pectoris rather than COPD were selected and thus over-represented in the cohort. Second, the current study included relatively young subjects who may not yet have developed manifest CAD. Finally, among the subjects who were excluded from the current study because of a known COPD diagnosis, the CAD comorbidity was high: nearly half of the subjects with a COPD diagnosis had also known CAD and 15\% were diagnosed with ischaemia at the myocardial perfusion imaging.

Still, the fact that the combination of COPD and myocardial ischaemia was uncommon is intriguing. Although not possible to be answered by the current study design, we speculate that COPD and CAD may in some cases represent two distinct pathophysiological pathways associated with the presence of similar risk factors, rather than a consequence of the same process with two different systems being equally affected. Although these factors are likely to be complex and could involve multiple mediating pathways, ${ }^{31}$ it may also be that specific subtypes of COPD, possibly with a larger component of emphysema, have a stronger association with concurrent atherosclerosis and thus CAD. ${ }^{32}$

By the current study design, chest discomfort was the most common presenting symptom. Chest discomfort is by itself not recognised as a central characteristic of COPD, and in the current study design, we were not able to discriminate between cases where chest pain was caused by COPD and cases where COPD was diagnosed without relation to the symptoms. Notably, in the vast majority of subjects reporting chest discomfort, neither reversible ischaemia nor COPD could be diagnosed. Unexplained chest discomfort is a common ${ }^{19}$ and often frustrating problem for the clinicians even though the patient can in most cases be reassured that the symptoms are not related to a severe cardiopulmonary disease. There may be a number of reasonable underlying causes in such patients including musculoskeletal, gastrointestinal 
(such as reflux or dyspepsia) and psychosomatic causes; however, it is reasonable to assume that in a minority of cases, a coronary cause such as a presence of microvascular angina may still provide the explanation. The high prevalence of typical chest pain without underlying cause in our middle-aged cohort warrants further research on the common clinical presentation of chest discomfort with normal coronary (and pulmonary) evaluation.

Our study has a number of important limitations that should be acknowledged. First, as already mentioned, we were not able to decide based on the current study design if COPD was actually a causative factor behind the symptoms or if COPD was a solely coincidental finding. Second, all patients who were diagnosed with COPD were informed of the finding and, if judged appropriate, referred for further evaluation and treatment. This precluded us from testing whether COPD screening as implemented in our study design led to improved symptoms or prognosis, which would ideally have required a blinded randomised design. Third, in approximately $5 \%$ of the patients, spirometry revealed a non-specific lung function reduction. The fact that total lung capacity was not measured precluded us from exploring the specific background in these cases, which might have been a restrictive pattern caused by either primary pulmonary disease or other underlying causes such as heart failure. Fourth, our study included only patients referred for elective ischaemia testing, meaning that the analysed cohort may not be representative for subjects who are usually seen in the emergency department and, further, admitted to the hospital.

In conclusion, among middle-aged patients with suspected stable myocardial ischaemia, previously undiagnosed COPD according to spirometry criteria can be found in $10 \%-30 \%$ of patients, depending on the applied criteria. In these patients, previously unrecognised airflow obstruction is at least as common as the reversible myocardial ischaemia. Whereas a history of smoking associates with previously undiagnosed COPD, the presenting symptoms in the form of chest discomfort or dyspnoea do not differentiate between previously undiagnosed COPD and ischaemia. Patients with unexplained symptoms suggestive of stable myocardial ischaemia may benefit from additional respiratory function tests in the form of dynamic spirometry, especially if there is a positive history of smoking.

Acknowledgements The authors would like to thank the staff at the Department of Clinical Physiology and Nuclear Medicine at Skåne University Hospital in Malmö, Sweden for their dedicated work with the BiG CaPPS cohort recruitment. We would also like to thank the staff at the Clinical Research Unit (KFE) at Skåne University Hospital in Malmö, Sweden.

Contributors All authors participated in (1) conception and design or analysis and interpretation of data, (2) drafting of the manuscript or revising it critically, and (3) final approval of the manuscript submitted. VH is responsible for the overall content as guarantor.

Funding This study was supported by grants from the Swedish Heart and Lung Foundation, Medical Faculty of Lund University, ALF funds, Skåne University Hospital Funds, Crafoord Foundation, Ernhold Lundströms Research Foundation, Region
Skåne, Hulda and Conrad Mossfelt Foundation, and Anna-Lisa and Sven Eric Lundgrens Foundation for Medical Research.

Competing interests VH is a shareholder in Investor AB (AstraZeneca and Swedish Orphan Biovitrum)

Patient consent Obtained.

Ethics approval The Regional Ethical Review Board in Lund, Sweden (Dnr 2013/242).

Provenance and peer review Not commissioned; externally peer reviewed.

Open access This is an open access article distributed in accordance with the Creative Commons Attribution Non Commercial (CC BY-NC 4.0) license, which permits others to distribute, remix, adapt, build upon this work non-commercially, and license their derivative works on different terms, provided the original work is properly cited, appropriate credit is given, any changes made indicated, and the use is non-commercial. See: http://creativecommons.org/licenses/by-nc/4.0/

\section{REFERENCES}

1. World Health Organization, 2015. WHO Fact sheet: top 10 causes of death globally. Available from: http://www.who.int/mediacentre/ factsheets/fs310/en/index.html

2. Lange $P$, Nyboe J, Appleyard M, et al. Spirometric findings and mortality in never-smokers. J Clin Epidemiol 1990;43:867-73.

3. Hole DJ, Watt GC, Davey-Smith G, et al. Impaired lung function and mortality risk in men and women: findings from the Renfrew and Paisley prospective population study. BMJ 1996;313:711-5. discussion 5-6.

4. Curkendall SM, DeLuise C, Jones JK, et al. Cardiovascular disease in patients with chronic obstructive pulmonary disease, Saskatchewan Canada cardiovascular disease in COPD patients. Ann Epidemiol 2006;16:63-70.

5. Feary JR, Rodrigues LC, Smith CJ, et al. Prevalence of major comorbidities in subjects with COPD and incidence of myocardial infarction and stroke: a comprehensive analysis using data from primary care. Thorax 2010;65:956-62.

6. Ko FW, Yan BP, Lam YY, et al. Undiagnosed airflow limitation is common in patients with coronary artery disease and associated with cardiac stress. Respirology 2016;21:137-42.

7. Soriano JB, Rigo F, Guerrero D, et al. High prevalence of undiagnosed airflow limitation in patients with cardiovascular disease. Chest 2010;137:333-40.

8. Jiménez-Ruiz CA, Andreas S, Lewis KE, et al. Statement on smoking cessation in COPD and other pulmonary diseases and in smokers with comorbidities who find it difficult to quit. Eur Respir J 2015;46:61-79.

9. Lamprecht B, McBurnie MA, Vollmer WM, et al. COPD in never smokers: results from the population-based burden of obstructive lung disease study. Chest 2011;139:752-63.

10. Sabater-Lleal M, Mälarstig A, Folkersen L, et al. Common genetic determinants of lung function, subclinical atherosclerosis and risk of coronary artery disease. PLoS One 2014;9:e104082.

11. Hagstad S, Backman H, Bjerg A, et al. Prevalence and risk factors of COPD among never-smokers in two areas of Sweden-occupational exposure to gas, dust or fumes is an important risk factor. Respir Med 2015;109:1439-45.

12. van Eeden SF, Sin DD. Chronic obstructive pulmonary disease: a chronic systemic inflammatory disease. Respiration 2008;75:224-38.

13. Ricci F, Wollmer P, Engström G, et al. Markers of cardiovascular autonomic dysfunction predict COPD in middle-aged subjects. Eur Respir J 2018;51:1702481.

14. Mapel DW, Dedrick D, Davis K. Trends and cardiovascular comorbidities of COPD patients in the Veterans Administration Medical System, 1991-1999. COPD 2005;2:35-41.

15. Cazzola M, Calzetta L, Matera MG, et al. Chronic obstructive pulmonary disease and coronary disease: COPDCoRi, a simple and effective algorithm for predicting the risk of coronary artery disease in COPD patients. Respir Med 2015;109:1019-25.

16. Arnett DK, Goodman RA, Halperin JL, et al. AHA/ACC/HHS strategies to enhance application of clinical practice guidelines in patients with cardiovascular disease and comorbid conditions: from the American Heart Association, American College of Cardiology, and U.S. Department of Health and Human Services. J Am Coll Cardiol 2014;64:1851-6.

17. Task Force Members, Montalescot G, Sechtem U, et al. 2013 ESC guidelines on the management of stable coronary artery disease: the Task Force on the management of stable coronary artery disease of the European Society of Cardiology. Eur Heart J 2013;34:2949-3003. 
18. Trägårdh E, Tan SS, Bucerius J, et al. Systematic review of costeffectiveness of myocardial perfusion scintigraphy in patients with ischaemic heart disease: a report from the cardiovascular committee of the European Association of Nuclear Medicine. Endorsed by the European Association of Cardiovascular Imaging. Eur Heart $J$ Cardiovasc Imaging 2017;18:825-32.

19. Reinhardt SW, Lin CJ, Novak E, et al. Noninvasive cardiac testing vs clinical evaluation alone in acute chest pain: a secondary analysis of the ROMICAT-II randomized clinical trial. JAMA Intern Med 2018;178:212-9.

20. Verberne HJ, Acampa W, Anagnostopoulos C, et al. EANM procedural guidelines for radionuclide myocardial perfusion imaging with SPECT and SPECT/CT: 2015 revision. Eur J Nucl Med Mol Imaging 2015;42:1929-40.

21. Trägårdh $\mathrm{E}$, Hesse $\mathrm{B}$, Knuuti $\mathrm{J}$, et al. Reporting nuclear cardiology: a joint position paper by the European Association of Nuclear Medicine (EANM) and the European Association of Cardiovascular Imaging (EACVI). Eur Heart J Cardiovasc Imaging 2015;16:272-9.

22. Edenbrandt L, Ohlsson M, Trägårdh E. Prognosis of patients without perfusion defects with and without rest study in myocardial perfusion scintigraphy. EJNMMI Res 2013;3:58.

23. Miller MR, Hankinson J, Brusasco V, et al. Standardisation of spirometry. Eur Respir J 2005;26:319-38.

24. Global Initiative for Chronic Obstructive Lung Disease, 2018. From the Global Strategy for the Diagnosis, Management and Prevention of COPD, Global Initiative for Chronic Obstructive Lung Disease (GOLD). Available from: http://goldcopd.org

25. Hedenström H, Malmberg P, Agarwal K. Reference values for lung function tests in females. Regression equations with smoking variables. Bull Eur Physiopathol Respir 1985;21:551-7.

26. Hedenström H, Malmberg P, Fridriksson HV. Reference values for lung function tests in men: regression equations with smoking variables. Ups J Med Sci 1986;91:299-310.

27. Pellegrino R, Viegi G, Brusasco V, et al. Interpretative strategies for lung function tests. Eur Respir J 2005;26:948-68.

28. Soriano JB, Zielinski J, Price D. Screening for and early detection of chronic obstructive pulmonary disease. Lancet 2009;374:721-32.

29. Güder G, Brenner S, Angermann CE, et al. GOLD or lower limit of normal definition? A comparison with expert-based diagnosis of chronic obstructive pulmonary disease in a prospective cohortstudy. Respir Res 2012;13:13.

30. Wollmer P, Frantz S, Engström G, et al. Fixed ratio or lower limit of normal for the FEV 1 NC ratio: relation to symptoms and extended lung function tests. Clin Physiol Funct Imaging 2017;37:263-9.

31. Boschetto $P$, Beghé $B$, Fabbri LM, et al. Link between chronic obstructive pulmonary disease and coronary artery disease: implication for clinical practice. Respirology 2012;17:422-31.

32. Frantz $\mathrm{S}$, Nihlén $\mathrm{U}$, Dencker $\mathrm{M}$, et al. Atherosclerotic plaques in the internal carotid artery and associations with lung function assessed by different methods. Clin Physiol Funct Imaging 2012;32:120-5. 


\section{Correction: High prevalence of undiagnosed COPD among patients evaluated for suspected myocardial ischaemia}

Jönsson A, Fedorowski A, Engström G, et al. High prevalence of undiagnosed COPD among patients evaluated for suspected myocardial ischaemia. Open Heart 2018;5:e000848. doi: 10.1136/openhrt-2018-000848

The authors want to alert readers to the following error identified in the published version.

At page 5 Table 2A and Table 2B are duplicate.

The Table 2B should be as below:

Table 2B Clinical characteristics and presenting symptoms according diagnoses (LLNcriteria)

\begin{tabular}{|c|c|c|c|c|c|c|}
\hline & $\begin{array}{l}\text { COPD + } \\
\text { Ischemia - } \\
(n=42)\end{array}$ & $\begin{array}{l}\text { COPD - } \\
\text { Ischemia + } \\
(n=51)\end{array}$ & $\begin{array}{l}\text { COPD + } \\
\text { ischemia } \\
+(n=4)\end{array}$ & $\begin{array}{l}\text { Other } \\
\text { spirometry } \\
\text { finding + } \\
\text { Ischemia - } \\
(\mathrm{n}=22)\end{array}$ & $\begin{array}{l}\text { Normal } \\
\text { findings } \\
(n=281)\end{array}$ & $P$ value \\
\hline Age, mean (SD) & $67.7(10.3)$ & $66.4(8.1)$ & $65.8(4.6)$ & $65.3(11.7)$ & $66.1(10.9)$ & 0.902 \\
\hline Sex, \% women & 61.9 & 19.6 & 25.0 & 36.4 & 47.7 & $<0.001$ \\
\hline Ever-smoker, \% & 73.2 & 78.4 & 100.0 & 63.6 & 60.6 & 0.044 \\
\hline $\begin{array}{l}\text { Current-smoker, } \\
\%\end{array}$ & 24.4 & 13.7 & 50.0 & 9.1 & 9.3 & 0.008 \\
\hline Known CAD, \% & 31.0 & 54.9 & 100.0 & 59.1 & 27.9 & $<0.001$ \\
\hline $\begin{array}{l}\text { Chest } \\
\text { discomfort, \% }\end{array}$ & 61.9 & 76.5 & 50.0 & 63.6 & 74.0 & 0.294 \\
\hline Dyspnea, \% & 21.4 & 11.8 & 25.0 & 9.1 & 18.9 & 0.533 \\
\hline $\begin{array}{l}\text { FEV1 \% of } \\
\text { predicted }\end{array}$ & $74.8(15.1)$ & $95.1(15.3)$ & $59.5(15.4)$ & $78.9(13.9)$ & $96.0(13.6)$ & $<0.001$ \\
\hline $\begin{array}{l}\text { VC \% of } \\
\text { predicted }\end{array}$ & $97.5(17.0)$ & $91.9(11.3)$ & $78.9(13.8)$ & 73.7 (10.1) & $96.0(12.2)$ & $<0.001^{\star}$ \\
\hline $\mathrm{BMI}, \mathrm{kg}^{*} \mathrm{~m}^{-2}$ & $29.2(5.2)$ & $29.7(4.5)$ & $26.1(4.6)$ & $30.1(5.1)$ & $28.0(4.4)$ & 0.023 \\
\hline $\begin{array}{l}\text { Dyslipidaemia, } \\
\%\end{array}$ & 38.1 & 52.9 & 50.0 & 40.9 & 35.2 & 0.196 \\
\hline SBP, mmHg & $138.1(16.2)$ & $142.2(17.3)$ & $131.3(17.0)$ & $142.7(15.3)$ & $138.1(17.7)$ & 0.370 \\
\hline $\mathrm{DBP}, \mathrm{mmHg}$ & $79.9(8.3)$ & $79.8(8.2)$ & $85.0(5.8)$ & $82.1(12.3)$ & $79.7(9.1)$ & 0.624 \\
\hline Heart rate, bpm & $72.5(11.7)$ & $71.0(11.2)$ & $70.3(14.1)$ & 70.9 (14.2) & 68.5 (11.5) & 0.230 \\
\hline
\end{tabular}

$P$ values are reported for ANOVA test for continuous variables and $\mathrm{chi}^{2}$ for dichotomous variables, unless otherwise specified.

${ }^{*} \mathrm{P}$ value reported for Welch ANOVA test due to inhomogeneity of variances between groups.

BPM, beats per minute; CAD, coronary artery disease; DBP, diastolic blood pressure; DLCO, diffusion capacity for carbon monoxide; FEV1, forced expiratory volume in one second;LLN, lower limit of normal; SBP, systolic blood pressure; VC, vital capacity.

Open access This is an open access article distributed in accordance with the Creative Commons Attribution Non Commercial (CC BY-NC 4.0) license, which permits others to distribute, remix, adapt, build upon this work non-commercially, and license their derivative works on different terms, provided the original work is properly cited, appropriate credit is given, any changes made indicated, and the use is non-commercial. See: http://creativecommons.org/licenses/by-nc/4.0/.

C Author(s) (or their employer(s)) 2019. Re-use permitted under CC BY-NC. No commercial re-use. See rights and permissions. Published by BMJ.

Open Heart 2019;6:0. doi:10.1136/openhrt-2018-000848corr1

\section{Check for updates}

